\title{
Relações público-privadas na educação pública: as implicações dos convênios para a Educação Infantil no município de Campo Grande, MS
}

\section{Public-private relations in public education: the implications of the agreements for early childhood education in the municipality of Campo Grande, MS}

Relaciones público-privadas en la educación pública: las implicaciones de los convenios para la educación infantil en el municipio de Campo Grande, MS

Solange Jarcem Fernandes ${ }^{1}$

Andrêssa Gomes de Rezende Alves ${ }^{2}$

Elayne Silva Viana ${ }^{1}$

DOI: http://dx.doi.org/10.20435/serie-estudos.v26i56.1393

Resumo: Este trabalho analisou a relação público-privada entre o município de Campo Grande, MS, e a Sociedade Caritativa e Humanitária (Seleta) em relação aos convênios firmados no período de 1997 a 2016. A parceria teve como objeto a prestação de serviços socioeducativos para preservação e ampliação das ações de atendimento à criança e ao adolescente em regime de cooperação com a Secretaria Municipal de Educação (SEMED). Esses convênios foram encerrados em dezembro de 2016, quando o Ministério Público do Estado de Mato Grosso do Sul (MPMS) impetrou uma Ação Civil Pública que culminou com a demissão de trabalhadores que prestavam serviços nos Centros de Educação Infantil (CEINFs). Como procedimento metodológico, foram realizadas consultas à legislação educacional em âmbito federal e municipal, aos documentos produzidos pelo município de Campo Grande, MS, aos documentos do MPMS e do TJMS e à literatura da área. Conclui-se que as transferências das ações estatais para uma entidade de caráter privado alteraram a responsabilidade do município em realizar concurso público para a contratação de trabalhadores para atuar nos CEINFs, ferindo-se o artigo 37 da Constituição Federal de 1988, pois não foi observado o caráter de excepcionalidade previsto na Constituição Federal de 1988.

Palavras-chave: Educação Infantil; parceria público-privada; convênios.

\footnotetext{
1 Universidade Federal de Mato Grosso do Sul (UFMS), Campo Grande, Mato Grosso do Sul, Brasil.

2 Universidade Estadual de Mato Grosso do Sul (UEMS), Mundo Novo, Mato Grosso do Sul, Brasil.
} 
Abstract: This work analyzed the public-private relations between the municipality of Campo Grande, MS, and the Charitable and Humanitarian Society (Seleta) concerning the agreements signed from 1997 to 2016 . The partnership had as its object the provision of educational services for the preservation and expansion of the actions of assistance to the child and the adolescent in cooperation with the Municipal Education Department (SEMED). These agreements were closed in December 2016, when the Prosecution Service of the State of Mato Grosso do Sul (MPMS) filed a Public Civil Action that culminated in the dismissal of workers who provided services at Centers for Early Childhood Education (CEINFs). Like a methodological procedure, consultations were made with the educational legislation at the federal and municipal levels, the documents produced by the municipality of Campo Grande, MS, the MPMS and the TJMS documents, and the literature of the area. We concluded that transfers of state actions to a private entity altered the municipality's responsibility to hold a public tender for the hiring of workers to perform in the CEINFs, violated Article 37 of the Federal Constitution of 1988 since it did not observe the character of exceptionality foreseen in the Federal Constitution of 1988.

Keywords: Early Childhood Education; public-private partnership; agreements.

Resumen: Este trabajo analizó la relación público-privada entre el municipio de Campo Grande, MS, y la Sociedad Caritativa y Humanitaria (Seleta) en relación a los convenios firmados en el período de 1997 a 2016. La asociación tuvo como objeto la oferta de servicios socio educativos para preservación y ampliación de las acciones de atendimiento a los niños y adolescentes en régimen de cooperación con la Secretaria Municipal de Educación (SEMED). Esos convenios fueron finalizados en diciembre de 2016, cuando el Ministerio Público del Estado de Mato Grosso do Sul (MPMS) presentó una demanda de Acción Civil Pública que culminó con el despido de trabajadores que prestaban servicios en los Centros de Educación Infantil (CEINFs). Como procedimiento metodológico, fueron realizadas consultas a la legislación educacional en ámbito nacional y municipal, a los documentos producidos por el municipio de Campo Grande, MS, a los documentos do MPMS y del TJMS y la literatura del área. Concluyese que las transferencias de las acciones estatales para una entidad de carácter privado alteraron la responsabilidad del municipio en realizar o concurso público para la contratación de trabajadores para actuar en los CEINFs, y se vulneró el artículo 37 de la Constitución Federal de 1988, pues no fue considerado el carácter de excepcionalidad previsto en la Constitución Federal de 1988.

Palabras clave: Educación Infantil; alianzas público-privada; convenios.

\section{INTRODUÇÃO}

Este trabalho analisou a relação público-privada entre o município de Campo Grande, MS, e a entidade filantrópica Sociedade Caritativa e Humanitária (Seleta), nos convênios firmados entre ambos, tendo como objeto a prestação de serviços socioeducativos para preservação e ampliação das ações de atendimento à criança e ao adolescente, em regime de cooperação mútua com a Secretaria Municipal de Educação (SEMED). Esses convênios foram celebrados de 1997 até o ano de 2016 e tinham como finalidade a contratação temporária de trabalhadores para 
Relações público-privadas na educação pública: as implicações dos convênios para a Educação Infantil no município de Campo Grande, MS

atuarem, principalmente, nos Centros de Educação Infantil (CEINFs), no qual desenvolviam trabalhos administrativos, de recreadores, de educadores ${ }^{3}$ e de técnicos administrativos em escolas da educação básica do município.

A parceria entre o município e a entidade encerrou-se em dezembro de 2016, quando o Ministério Público do Estado de Mato Grosso do Sul (MPMS) impetrou uma Ação Civil Pública contra a entidade Seleta, a Organização Mundial para Educação Pré-Escolar (OMEP) de Campo Grande, MS, e o município de Campo Grande, ocasião em que foram demitidos 4.369 (quatro mil trezentos e sessenta e nove) trabalhadores das duas entidades filantrópicas. Da entidade Seleta, eram 2.351 (dois mil trezentos e cinquenta e um) trabalhadores, e desses, 2.080 (dois mil e oitenta) prestavam serviços na Educação Infantil nos CEINFs.

Os convênios, na sua parte formal, observavam a legislação vigente - Lei n. 8.666/1993, Lei n. 11.494/2007, Decretos n. 6.253/2007 e n. 7.761/1998 e Lei Municipal n. 3.146/1995 - porém, na sua execução, não observavam a legislação, burlando vários itens dos contratos acordados: manteve-se, desde o ano de 1997 até 2016, a contratação de trabalhadores de formas sucessivas e ininterruptas com a instituição, em detrimento da Constituição Federal de 1988, artigo 37, que coloca a necessidade de concurso público para a contratação de servidores para exercerem atividades-fim e que determina que contratações fora de concurso público devem ocorrer somente em caráter excepcional.

Esta Ação Civil Pública e os seus desdobramentos corroboram as análises na área de educação, em relação aos efeitos e impactos relacionados às temáticas que analisam a relação entre público e privado na educação (ADRIÃO; PERONI, 2009; MONTAÑO, 2010), com questões específicas sobre o instrumento convênio e a atuação do terceiro setor, alçados como parceiros que influenciam diretamente na gestão e na organização das redes públicas de ensino, a partir da lógica da nova gestão pública, que ganha centralidade na década de 1990, no bojo da reforma do Estado brasileiro.

Os documentos analisados que foram produzidos pelo MPMS e pelo Tribunal de Justiça de Mato Grosso do Sul (TJMS) como parte da Ação Civil Pública indicavam que havia violação à legislação vigente, violação aos princípios da administração

${ }^{3}$ Educador foi um termo genérico utilizado nos documentos de demissão elaborado pela Secretaria de Assistência Social do Município de Campo Grande, não indicando quais eram o cargo e a função exercidos pelo profissional, tampouco o nível de escolaridade (MATO GROSSO DO SUL, 2016a). 
pública, danos ao erário público e abuso de direito na implementação do convênio (MATO GROSSO DO SUL, 2016a).

Essa ação, de um lado, mesmo que tardiamente, procurou resolver uma situação irregular no uso do instrumento convênio para contratação de pessoal, constatando que havia um número elevado de pessoas atuando na administração pública, realizando funções relacionadas à atividade-fim ${ }^{4}$, pagas com recursos públicos e sem a condição de caráter excepcional que devia ser observada no artigo 37 da Constituição Federal de 1988 (BRASIL, 1988) e na legislação do município de Campo Grande, na Lei Complementar municipal n. 190/2011, artigos 292 e 293 (CAMPO GRANDE, 2011). Indicava também que o dinheiro público estava sendo usado de forma irregular para o pagamento de funcionários da entidade, com o recebimento de comissão de 5\% sobre os custos mensais dos convênios para uma entidade sem fins lucrativos.

Por outro lado, os efeitos dessa ação foram prejudiciais aos trabalhadores demitidos em um processo único, sem garantias de recebimento do salário mensal, décimo terceiro salário e as garantias trabalhistas; para as crianças matriculadas nos CEINFs e também para os pais dos alunos, pois houve interrupções de grande parte dos atendimentos como consequência da demissão dos trabalhadores sem um prévio planejamento por parte do ente público. Ou seja, mesmo havendo indicativos ao longo do processo analisado (2013 a 2016) de que o desfecho seria a demissão dos trabalhadores e de que havia a necessidade de realização de concursos públicos, os trabalhadores constataram que as informações que foram noticiadas pelas mídias locais de que o município e a entidade filantrópica não tinham recursos para pagar os salários vencidos, o 13으 salário e os direitos trabalhistas eram verdadeiras, fato que gerou um grave problema de ordem educacional, trabalhista e social no município.

Para elucidar esta opção político-administrativa do município com efeito nas políticas educacionais, em específico, uma opção que afetará a gestão e a organização da etapa da Educação Infantil, delegando que uma parte significativa da sua força de trabalho será contratada via parceria público-privada para desempenhar funções administrativas e também de cunho pedagógico, modifica-se o desenho

4 Com a nova legislação, Lei n. 13.429, de 31 de março de 2017, qualquer atividade da empresa urbana poderá ser terceirizada, inocorrendo qualquer forma de restrição existente em relação ao exercício de atividade-fim (BRASIL, 2017). 
da política educacional, principalmente os relacionados às diretrizes delineadas como princípios da educação nacional, como o princípio da gestão democrática e o da valorização dos profissionais da educação, por exemplo.

Dessa forma, este estudo está situado no contexto da reconfiguração do Estado brasileiro, a qual, na década de 1990, apresentou-se como estratégia para a superação da chamada crise dos Estados Nacionais e que tem na reforma do Estado a justificativa para diminuir a sua atuação ante as políticas públicas de cunho social. Com isso, ocorre a transferência da responsabilidade da questão social do Estado para a sociedade, por meio de parcerias público-privadas.

Proposta de Reforma de Estado expressa no documento do Ministério da Administração e Reforma do Estado, o Plano Diretor da Reforma do Aparelho do Estado (PDRAE), em 1995, esteve em sintonia com o ideário neoliberal e tinha, entre os seus objetivos, a modernização e superação da gestão burocrática pela gerencial. A reestruturação da administração pública, pela via da reforma, provocou modificações, as quais se desdobraram nas políticas sociais, criando ambientes favoráveis para as parcerias por meio de contratos entre o Estado e as empresas privadas ou organizações sociais de caráter não lucrativo e não governamental. Mesmo que a política educacional não seja exclusivamente determinada pelas mudanças que ocorrem na redefinição do papel do Estado, ela é parte constitutiva dessas transformações (PERONI, 2015), pois a redefinição do papel do Estado faz parte de um processo maior inserido na crise do capital.

Como procedimentos metodológicos na elaboração deste artigo, foram realizadas consultas à legislação em âmbito federal e municipal, aos documentos produzidos pelo município de Campo Grande, MS, aos documentos produzidos pelo MPMS, à sentença do TJMS e à literatura pertinente à área. Elegeu-se como categoria de análise a historicidade, que permitiu verificar o entretempo de 1997 a 2016, quando houve a realização sucessiva dos convênios entre o ente público e a entidade filantrópica e foram adotadas medidas pelo MPMS.

\section{A RELAÇÃO PÚBLICO-PRIVADA: OS CONVÊNIOS CELEBRADOS PELO MUNICÍPIO E A INSTITUIÇÃO SELETA}

A partir da reforma do Estado instituída nos anos de 1990, com o Plano Diretor da Reforma do Aparelho do Estado, as políticas sociais foram consideradas serviços não exclusivos do Estado, isto é, o Estado deixou de ser o responsável 
direto pelo desenvolvimento econômico e social, para fortalecer-se na função de promotor e regulador desse desenvolvimento.

A reforma do Estado brasileiro foi fundamental para que o chamado terceiro setor ganhasse força, a partir das estratégias de descentralização, privatização e focalização das políticas públicas. Esses mecanismos instrumentalizaram as parcerias entre o setor público e a esfera privada, alterando as ações do Estado como promotor das políticas sociais. O modelo gerencial passou a ser referência para a estruturação administrativa e também para os processos que permeiam a educação. Esse modelo entrou nas instituições a partir de medidas adotadas pelos governos e disseminou a proposta do projeto neoliberal, concentrando elementos necessários à formação do trabalhador, bem como meios que subsidiam as políticas sociais e a gestão da educação.

Peroni (2018) aponta as várias formas de privatização do público: alteração da propriedade, com a passagem do estatal para o terceiro setor ou privado; parcerias entre instituições públicas e privadas com ou sem fins lucrativos, processo em que o privado acaba definindo o público; ainda, quando permanece com a propriedade estatal, mas com a lógica de mercado, que reorganiza principalmente os processos de gestão e redefinindo o conteúdo da política educacional.

Essa transferência das políticas sociais ao terceiro setor abre caminho para atuação das instituições não estatais, como ONGs, fundações e institutos. Essas instituições assumem a função do Estado na direção e execução das políticas, programas, projetos e ações, constituindo-se por meio das chamadas parcerias entre o Estado e organizações da sociedade civil que planejam e executam as políticas destinadas à área social.

A minimização das ações do Estado ocorre a partir de diferentes modalidades de cooperação e financiamento para viabilizar a atuação das organizações do terceiro setor. Esses mecanismos são definidos por Montaño (2010, p. 205) pela isenção de impostos, ou pela renúncia fiscal do Estado para entidades declaradas como instituições filantrópicas ou de interesse público, conforme a Lei n. 9.732/1998. E, também, conforme pontua Szazi (2006), por meio dos mecanismos de

Auxílios e contribuições. Os auxílios derivam diretamente da Lei do Orçamento; as contribuições definem-se por lei especial. [...] Subvenções sociais. Destinadas a cobrir despesas de custeio de entidades públicas ou privadas, sem fins lucrativos, para a prestação de serviços de assistência 
Relações público-privadas na educação pública: as implicações dos convênios para a Educação Infantil no município de Campo Grande, MS

social, médica e educacional. [...] Convênios, acordos ou ajustes. São o meio jurídico adequado para a execução, em regime de mútua cooperação, de serviços de recíproco. [...] Contratos de gestão. A partir da Lei no 9.637, o Estado destina recursos para que uma entidade privada sem fins lucrativos, sem processo licitatório, realize atividades públicas. Na verdade, isto representa uma verdadeira privatização, mediante a terceirização ou a transferência de funções de responsabilidade estatal para a chamada "iniciativa privada". [...] Termos de parceria. Seguindo o que reza a Lei $n$ o 9.790, o Estado transfere recursos públicos para a entidade "parceira". Isto, quando é feito de forma a substituir (não complementar) a responsabilidade estatal com a resposta às demandas sociais, é outra forma de privatização de funções do Estado (SZAZI, 2006, p. 103-9). (Grifo das autoras).

Na gestão gerencial, a expansão das parcerias envolve atores privados que assumem funções no setor público, como o da definição de políticas, da oferta da educação e da fiscalização, e, ainda, atuam na gestão escolar, como na dos sistemas de ensino. A inserção de critérios privados na gestão do público se apresenta como um meio de inovar o financiamento da educação "[...] que se baseia no melhor do público e do privado como potencial para resolver os profundos problemas sistêmicos dos sistemas de ensino, tais como acesso, qualidade e equidade" (ROBERTSON; VERGER, 2012, p. 1135).

Robertson e Verger (2012) denominam também a relação entre o Estado e o mercado como parcerias público-privadas em que o Estado deixa de ser o provedor direto, pois continua financiando as políticas públicas para tornar-se o regulador das políticas públicas e sociais. Entendem esse processo de parcerias como um

[...] guarda-chuva perfeito, pois enquanto o propósito subjacente e as lógicas de gestão da educação são garantidos de acordo com a lógica de mercado, dada a presença do setor privado como responsável pela oferta, o Estado assegura o ambiente político favorável e, o mais importante, o seu financiamento. (ROBERTSON; VERGER, 2012, p. 1143).

Os mecanismos convênio, o contrato de gestão e o termo de parceria (SZAZI, 2006) estão presentes na relação que o município estabeleceu ao transferir recursos públicos para a entidade Seleta na contratação de trabalhadores, substituindo a responsabilidade estatal como resposta às demandas sociais. Ressalte-se que parcerias são formalizadas por meio de contratos que variam conforme o tipo de serviço prestado, que vão desde a construção, gestão e manutenção, até a própria prestação de serviços. E uma das suas bases 
é flexibilizar os processos de valorização e acumulação do capital e, consequentemente, desvalorizar a força de trabalho.

Desde o ano de 1997, o instrumento convênio entre o município de Campo Grande, MS, e as entidades filantrópicas se configurou na principal opção do município para contratar trabalhadores para a prestação de serviços no atendimento a crianças e adolescentes, principalmente para atuarem na Educação Infantil, com o argumento de imprimir qualidade e celeridade nas atividades dos CEINFs. Por essa opção do município, ficam evidentes os argumentos imprimidos pela gestão gerencial, que atribuem ao setor público a característica de ser ineficiente na gestão da coisa pública e que apontam estar expresso no documento PDRAE que o Estado brasileiro enfrenta um problema de governança, “[...] na medida em que sua capacidade de implementar as políticas públicas é limitada pela rigidez e ineficiência da máquina administrativa" (BRASIL, 1995, p. 14).

A Ação Civil Pública desmonta essa argumentação, pois trouxe a público uma das limitações nas relações entre o público e o privado. Ressaltamos que a intervenção do MPMS encerrou uma situação que não imprimiu qualidade e não contribuiu para a efetivação do direito à educação. Ao contrário, corroborou a má utilização do dinheiro público e prejuízo aos trabalhadores que atuavam nas atividades-fim, entre eles os que desenvolviam a função pedagógica que, em última instância, poderiam se beneficiar dos Planos de Cargos e Carreiras inerentes aos profissionais concursados, bem como gozar de melhores condições salariais.

A incorporação da lógica privada no sistema público ocorreu por meio de aspectos legais que dispõem sobre o Terceiro Setor no Brasil. A Lei n. 9.790/1999 (BRASIL, 1999) institui a atuação das Organizações da Sociedade Civil de Interesse Público (OSCIPS) e torna o Estado um parceiro na promoção das políticas sociais. Em 2002, o novo Código Civil atualizou a legislação. As entidades do Terceiro Setor são regidas pelo Código Civil, Lei n. 10.406, de 10 de janeiro de 2002. Em 2004, ganha força, na Lei de Parcerias Público-Privadas, a Lei n. 11.079, de 30 de dezembro de 2004, que institui normas para a licitação e contratação de parcerias público-privadas no âmbito da administração pública (BRASIL, 2004). No contexto das parcerias, o Estado se torna o principal financiador das instituições do terceiro setor.

A Lei n. 13.019, de 31 de julho de 2014, alterada pela Lei n. 13.204, de 14 de dezembro de 2015, estabelece nova redação ao propor o regime jurídico das parcerias entre a administração pública e as organizações da sociedade civil, em 
regime de mútua cooperação, para a consecução de finalidades de interesse público e recíproco, mediante a execução de atividades ou de projetos previamente estabelecidos em planos de trabalho inseridos em termos de colaboração, em termos de fomento ou em acordos de cooperação; define diretrizes para a política de fomento, de colaboração e de cooperação com organizações da sociedade civil; e altera as Leis n. 8.429, de 2 de junho de 1992, e n. 9.790/1999 (BRASIL, 2015).

Sob o esse enfoque, foi possível perceber as mudanças nas relações entre Estado e sociedade civil. A perspectiva neoliberal de diminuição das atividades do Estado sobre as políticas sociais, por meio da privatização, da terceirização e de parcerias, tem para Montaño (2010) a real função ideológica de encobrir e gerar aceitação da população, que compactua com a estratégia de reestruturação do capital, com consequências para as conquistas da classe trabalhadora: direitos trabalhistas, políticas sociais, direitos democráticos.

O fato é que essa nova forma de gestão corrobora a manutenção do projeto hegemônico do capital, o neoliberalismo, bem como o esfacelamento dos direitos sociais historicamente conquistados, que, particularmente no caso brasileiro, com a conjuntura histórica constituída a partir dos anos de 1990 até a primeira década e meia do século XXI, o que temos é a destruição de direitos sociais e a precarização das políticas públicas encobertas pela agenda política dos governos.

A reforma do Estado, ao introduzir elementos da administração gerencial no âmbito estatal, passou a delegar ao setor privado e ao setor público não estatal atividades que até então Ihe eram específicas. Assim, as parcerias público-privadas, regulamentadas por lei, permitiram a ampliação dos acordos entre o poder público e entes não estatais, bem como a possibilidade de convênios na prestação de serviços educacionais (BRASIL, 2004).

A etapa da Educação Infantil do município de Campo Grande, principalmente o atendimento em CEINFs, nesse desenho gerencial das políticas públicas e sociais para o setor educacional, apresentou o cenário propício para a sua operacionalização ocorrer por meio de convênios. Esta observação se deve às constatações de que a Educação Infantil do município, historicamente, esteve ligada à assistência social e, com a Constituição Federal de 1988, essa situação pouco foi alterada. Na primeira Lei Orgânica do Município (LOM) de 1990, no capítulo dedicado à educação, somente a pré-escola era definida como etapa a ser atendida pela educação. Esta situação só foi revista em 2007, quando houve a modificação da 
LOM, e a Educação Infantil passou a ser observada conforme estabelece a LDBN n. 9.394/1996, com o município atuando prioritariamente no ensino fundamental e na Educação Infantil, e não somente no ensino fundamental e na pré-escola, conforme a redação original de 1990 (CAMPO GRANDE, 2007).

Essa mesma situação é observada no financiamento, pois, até o ano de 2006, havia quantidades expressivas de gastos orçamentários da subfunção Educação Infantil, lançados na Secretaria de Assistência Social, justificado pelo atendimento aos CEINFs na denominada gestão compartilhada. A partir do ano de 2007, devido à indução do Fundo de Manutenção e Desenvolvimento da Educação Básica e de Valorização dos Profissionais da Educação (Fundeb), esses gastos começaram a ser lançados na função educação (FERNANDES, 2013, p. 197).

Mesmo com a modificação da LOM e a indução do Fundeb em relação ao financiamento, a gestão continuou sendo compartilhada até o ano de 2014. Por esse mecanismo, a Secretaria de Educação não tinha a gestão plena da Educação Infantil, ela era responsável principalmente pela contratação de professores para atuar nos CEINFs cuidando da gestão pedagógica, ao passo que a gestão administrativa era de responsabilidade da Secretaria de Assistência Social, justamente onde se localizava número significativo das contratações de merendeiras, cuidadoras, recreadores e de outros trabalhadores necessários para o funcionamento das unidades. Somente em 2014 é que a Secretaria de Educação passou a ter a gestão plena da etapa da Educação Infantil; contudo as contratações por meio dos convênios continuaram a ocorrer.

\section{AS IRREGULARIDADES APRESENTADAS PELOS CONVÊNIOS FIRMADOS COM A SELETA}

Os convênios sucessivos celebrados tinham como objeto a prestação de serviços socioeducativos em regime de cooperação mútua com a Secretaria de Educação e a Secretaria de Políticas e Ações Sociais e Cidadania. Em relação à educação, a prestação de serviços visava à preservação e ampliação das ações de atenção e de atendimento a crianças nos CEINFs, por meio da contratação de trabalhadores para prestarem serviço nas unidades (CAMPO GRANDE, 2014).

A demissão dos 4.369 (quatro mil trezentos e sessenta e nove) trabalhadores recebeu ampla cobertura pela mídia local, envolveu o bloqueio de bens dos 
envolvidos e a prisão dos presidentes das entidades (Seleta e OMEP-MS). Causou também repercussão o movimento realizado pelos trabalhadores para pressionar o Executivo municipal a solucionar o impasse ocasionado pela demissão, trazendo à tona as dificuldades dos trabalhadores demitidos em época natalina, sem o recebimento de salários e dos direitos da rescisão contratual (MIDIAMAX, 2016).

A Ação Civil Pública trouxe a público outras irregularidades na operacionalização dos contratos. Segundo os documentos produzidos pelo MPMS, os convênios tiveram seus objetivos desvirtuados, "[...] pois os envolvidos teriam usado o convênio para contratar pessoas para as mais variadas funções [...]" (MATO GROSSO DO SUL, 2016a). Havia pessoas trabalhando em locais que não atendiam crianças e adolescentes, tais como Centros de Convivência de Idosos, Secretaria de Assistência Social, Procuradoria-Geral do Município, Associação do Banco do Brasil, entre outros. Foi previsto também o pagamento para a Seleta de $5 \%$ dos custos mensais para pagamento dos salários e encargos dos funcionários da própria instituição. Ou seja, além do valor recebido para o pagamento dos salários, a entidade ainda tinha os custos pagos pelo município, "[...] sendo inadmissível que o Município pague seus funcionários e que ainda a entidade receba uma 'comissão' sobre os salários dos funcionários que ela deveria pagar às suas expensas" (MATO GROSSO DO SUL, 2016a, p. 16). Na sentença, foi ressaltado que esses $5 \%$ representaram na "[...] visão da entidade (que ela) se focou no prisma de que quanto mais gente sendo remunerada pela prefeitura, maiores serão os rendimentos da entidade" (MATO GROSSO DO SUL, 2018).

Por parte do município, a administração desconhecia onde os trabalhadores estavam lotados, com contratações realizadas por indicação, sem processo seletivo, sem controle adequado do ponto, sem limites de contratações e sem uniformidade de salários ${ }^{5}$, entre outros pontos que não são objetos de análise deste artigo. Ainda, o documento informa que

[...] o município se beneficiou do convênio ao não pagar as contribuições sociais que são cobradas dos empregadores. Estas contribuições alcançariam $\mathrm{R} \$$ 800.000,00 por mês o que demonstra o lucro da Administração Pública;

\footnotetext{
${ }^{5}$ Os autos processuais estão disponíveis no site. Disponível em: https://esaj.tjms.jus.br/pastadigital/pg/abrirConferenciaDocumento.do, processo 0900932-91.2016.8.12.0001. Acesso em: 10 de jan. de 2018.
} 
[...] graças ao convênio, o município se beneficiou ao não computar os gastos com pessoal fixado na Lei de Responsabilidade Fiscal, já que as tais contratações não eram computadas (fls. 453). (MATO GROSSO DO SUL, 2018).

Segundo o documento, o município não tinha controle dos vínculos empregatícios e não administrava os pagamentos efetuados pelo convênio, desconhecendo a quantidade de trabalhadores e se efetivamente as pessoas contratadas estavam trabalhando, pois o controle de ponto era ineficaz.

Ainda, a Seleta, como entidade do terceiro setor, recebeu e gerenciou recursos públicos em montantes significativos ${ }^{6}$, ao mesmo tempo que era prestadora de serviços de utilidade pública, que a levou a fazer jus de alguns benefícios fiscais. Segundo a sentença, esta condição colocou a instituição sob o observado no artigo 1o da Lei n. 8.429/1992, como entidade cuja "[...] criação e custeio o erário haja concorrido ou concorra com mais de $50 \%$ do patrimônio ou da receita anual [...] no sentido mais amplo do termo que a Lei n. 8.429/1992 quis dar. Em última análise, gerenciaram pessoalmente vultosos recursos públicos" (MATO GROSSO DO SUL, 2018b).

Para Montaño (2010), a privatização e a descentralização dos processos de gestão e de prestação de serviços sociais e assistenciais pressupõem iniciativas distantes dos mecanismos democráticos no âmbito estatal: contratos temporários, inexistência de concursos públicos, inexistência de licitações públicas, inexistência de controles sociais sobre os gastos e recursos, garantia de descontinuidade dos serviços, entre outros processos.

Ainda, para esse autor, a atuação das organizações sociais por meio de parcerias representa a desresponsabilização do Estado ante as questões sociais, com a transferência para o setor privado, e visa ao esvaziamento do Estado, por meio da diminuição das atividades sociais, precarização dos serviços com a perda da dimensão de universalidade e desvalorização da força de trabalho, cancelando direitos trabalhistas e sociais.

Nos contratos firmados, foi determinado que as ações realizadas pela entidade deveriam obedecer às diretrizes de um Plano de Trabalho elaborado pela Secretaria Municipal de Educação, com base no Estatuto da Criança e do

\footnotetext{
6 A Seleta recebia um repasse de 5\% (cinco por cento) sobre o valor global de $\mathrm{R} \$ 3.400 .000,00$ (três milhões e quatrocentos mil reais), para operacionalização do convênio (MATO GROSSO DO SUL, 2018).
} 
Relações público-privadas na educação pública: as implicações dos convênios para a Educação Infantil no município de Campo Grande, MS

Adolescente (ECA), na Lei Orgânica de Assistência Social (LOAS), entre outras legislações (CAMPO GRANDE, 2014). Porém o Plano de Trabalho, que seria o direcionador das ações e que serviria como instrumento balizador das ações de cunho pedagógico e organizacional, tendo como fim parâmetros para um atendimento de qualidade, pois os valores repassados pelos convênios eram significativos, não constou do processo e nem foi localizado nos arquivos do município,

[...] aparentemente, nunca foi elaborado. Ao menos sempre foi ignorado na execução do convênio, porque os atos praticados se afastaram em muito dos objetivos e diretrizes previstas no convênio e, também, das atribuições institucionais da Seleta. (MATO GROSSO DO SUL, 2018).

Essas situações de irregularidades já eram recorrentes, como demonstra o documento do MPMS. Em 17 de agosto de 2011, foi emitido o primeiro Termo de Ajustamento de Conduta (TAC) com o município, que pedia a demissão dos trabalhadores contratados pelo convênio e a realização de concurso público para provimento dos cargos. O ajuste determinava prazo de noventa dias para ser cumprido e a contratação dos trabalhadores deveria ser por meio de concurso público (MATO GROSSO DO SUL, 2016b).

O TAC de 2011, assim como outro Termo Aditivo firmado em 21 de março de 2014, não foi cumprido pelo município e nem pela Seleta e, além do descumprimento, houve reincidência nas contratações, pois de 2014 a 2015, em vez da demissão dos trabalhadores, houve aumento no quantitativo de pessoal contratado, dobrando o número de contratos.

Diante disso, o MPMS ingressou com uma Ação Executiva (obrigação de fazer), na Segunda Vara de Direitos Difusos, Coletivos e Individuais Homogêneos, atendo-se

[...] às irregularidades no âmbito da SELETA, no que tange às contratações irregulares relativas aos Convênios firmados com o Município de Campo Grande-MS, bem como à demonstração da contribuição do gestor da entidade para que, por conveniência e vantagem financeira, a situação de contratações irregulares se mantivesse e evoluísse ao ponto de se ter milhares de funcionários remunerados pelo Poder Público sem que houvesse uma ação para que as ilegalidades se encerrassem. Não há que se falar somente em omissão, pois as ações tomadas pelo gestor da entidade demonstram total afinidade com a vontade dos gestores municipais (MATO GROSSO DO SUL, 2016b, p. 3). 
Como se observa, um dos argumentos foi a violação do inciso II do artigo 37 da CF/1988 ao realizar contratações ilimitadas de pessoas, muitas por indicação de terceiros (políticos ou não), não observando as formalidades da lei, e, ainda, pessoas contratadas para trabalhar como funcionários da entidade, que deveriam ter seus salários pagos por ela e, no entanto, eram remuneradas com verbas públicas do convênio (MATO GROSSO DO SUL, 2016a).

A legislação determina que a administração pública deve realizar concurso público com determinado número de vagas e com a nomeação destas. Em âmbito federal, a referida exceção ao concurso público foi regulamentada pela Lei

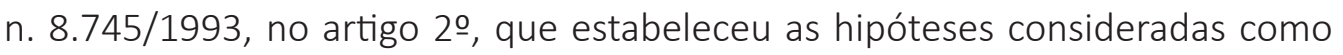
de necessidade temporária de excepcional interesse público (BRASIL, 1993). A Lei Complementar municipal n. 190/2011, artigo 292, determina que contratos temporários devem ocorrer somente em situações emergenciais, quando há necessidade de contratações para que serviços essenciais não sejam interrompidos, ou seja, a contratação por tempo determinado para atender à necessidade temporária e de excepcional interesse público é uma exceção que está prevista na CF/1988, portanto não pode ser prolongada ad infinitum (CAMPO GRANDE, 2011).

Esta Ação Civil Pública é anterior à Lei n. 13.429/2017, que normatiza sobre as atividades-meio e atividades-fim, bem como altera a legislação que dispõe sobre o trabalho temporário nas empresas urbanas. Em seu artigo 9으, parágrafo 3 o, regulamenta que "[...] O contrato de trabalho temporário pode versar sobre o desenvolvimento da atividade-meio e atividade-fim a serem executados na empresa tomadora de serviço" (BRASIL, 2017). No período de 1997 a 2016, a legislação não permitia as contratações temporárias para a atividade-fim, sendo esse um dos motivos que caracterizou a improbidade administrativa e a intervenção tardia do MPMS.

Dessa forma, as transferências das ações estatais para a entidade de caráter público-privada deslocaram as responsabilidades do Estado para a iniciativa privada, e o direito a uma educação de qualidade foi substituído por interesses escusos, como demonstram os documentos analisados e os processos instaurados. Neste caso específico, a parceria deixou para a educação e os trabalhadores da educação o ônus da ação. 


\section{ALGUMAS CONSIDERAÇÕES}

Os convênios ininterruptos entre o município e a Seleta não ocorreram em situações de necessidade excepcional de interesse público, como prevê o artigo 37 da Constituição Federal de 1988 (BRASIL, 1988). As constatações que se inferem da análise dos documentos são de que os contratos firmados se basearam na legislação que regulamenta as relações público-privadas, porém, na sua operacionalização, a entidade e o município utilizaram-se das prerrogativas e brechas criadas pela legislação das parcerias para a prática de atos ilícitos em relação ao uso da verba pública.

Na prática, segundo a sentença proferida em 2018, a instituição se converteu em uma agência de empregos, recebendo, além dos valores dos convênios, comissão sobre o custo mensal, apresentando apenas os nomes e os respectivos salários dos contratados, com total informalidade, impessoalidade e sem "[...] nenhum limite aparente ao número de pessoas contratadas" (MATO GROSSO DO SUL, 2018). E, por ser uma entidade filantrópica, esta não poderia obter lucro na prestação de serviços e no repasse e na distribuição da verba pública, violando a legislação e incorrendo em improbidade administrativa.

A demissão dos trabalhadores ocorreu entre os anos de 2016 e 2017. O MPMS ajuizou uma outra ação civil por ato de improbidade administrativa contra os ex-prefeitos do município de Campo Grande, Nelson Trad Filho (2005 a 2012), Alcides Jesus Peralta Bernal (2012 a 2013 e 2015 a 2016) e Gilmar Antunes Olarte (2014 a 2015). O ex-prefeito André Puccinelli foi beneficiado pela legislação vigente e não foi processado porque o período em que foi agente público municipal (1997 a 2004) está abrangido pela prescrição quinquenal, conforme prevê o artigo 23 da Lei n. 8.429/1992. Desta forma, ele deveria ter sido processado até 31/12/2009. A ação foi ajuizada de forma tardia, favorecendo-o (MATO GROSSO DO SUL, 2018a).

Conclui-se que o direito a uma educação de qualidade foi substituído por interesses mercantis, pois, com a introdução deste modelo gerencial de relação entre o ente estatal e o privado, a educação inserida nesse contexto não é mais compreendida como um serviço de exclusividade do Estado. 


\section{REFERÊNCIAS}

ADRIÃO, T.; PERONI, V. M. V. A educação pública e sua relação com o setor privado Implicações para a democracia educacional. Revista Retratos da Escola, Brasília, v. 3, n. 4, p. 107-116, jan./jun. 2009. Disponível em: http//www.esforce.org.br. Acesso em: 20 nov. 2017.

BRASIL. Lei n. 13.429, de 31 de março de 2017. Altera dispositivos da Lei n. 6.019, de 3 de janeiro de 1974, que dispõe sobre o trabalho temporário nas empresas urbanas e dá outras providências; e dispõe sobre as relações de trabalho na empresa de prestação de serviços a terceiros. Brasília-DF, 2017. Disponível em: http://www.planalto.gov.br/ ccivil_03/_Ato2015-2018/2017/Lei/L13429.htm. Acesso em: 2 dez. 2018.

BRASIL. Lei n. 13.204, 14 de dezembro de 2015. Altera a Lei n. 13.019, de 31 de julho de 2014, que estabelece o regime jurídico das parcerias voluntárias, envolvendo ou não transferências de recursos financeiros, entre a administração pública e as organizações da sociedade civil, em regime de mútua cooperação, para a consecução de finalidades de interesse público; define diretrizes para a política de fomento e de colaboração com organizações da sociedade civil; institui o termo de colaboração e o termo de fomento; e altera as Leis n. 8.429, de 2 de junho de 1992, e 9.790, de 23 de março de 1999; altera as Leis n. 8.429, de 2 de junho de 1992, 9.790, de 23 de março de 1999, 9.249, de 26 de dezembro de 1995, 9.532, de 10 de dezembro de 1997, 12.101, de 27 de novembro de 2009, e 8.666, de 21 de junho de 1993; e revoga a Lei n. 91, de 28 de agosto de 1935. Diário Oficial da União, Brasília-DF, 14 dez. 2015. Disponível em: http://www.planalto. gov.br/ccivil_03/_Ato2015-2018/2015/Lei/L13204.htm\#art1. Acesso em: 25 jun. 2017.

BRASIL. Lei n. 11.079, 30 de dezembro de 2004. Institui normas gerais para licitação e contratação de parceria público-privada no âmbito da administração pública. BrasíliaDF, 2004. Disponível em: http://www.planalto.gov.br/ccivil_03/_ato.htm. Acesso em: 20 out. 2017.

BRASIL. Lei n. 9.790, 23 de março de 1999. Dispõe sobre a qualificação de pessoas jurídicas de direito privado, sem fins lucrativos, como Organizações da Sociedade Civil de Interesse Público, institui e disciplina o Termo de Parceria, e dá outras providências. Diário Oficial da União. Brasília-DF, 23 mar. 1999. Disponível em: http://www.planalto.gov.br/ccivil_03/ leis/L9790.htm. Acesso em: 25 jun. 2017.

BRASIL. Ministério da Administração Federal e da Reforma do Estado. Plano diretor da reforma do aparelho do Estado. Brasília-DF, 1995.

BRASIL. Lei n. 8.745, 9 de dezembro de 1993. Dispõe sobre a contratação por tempo determinado para atender à necessidade temporária de excepcional interesse público, 
Relações público-privadas na educação pública: as implicações dos convênios para a Educação Infantil no município de Campo Grande, MS

nos termos do inciso IX do art. 37 da Constituição Federal. Brasil-DF, 1993. Disponível em: http://www.planalto.gov.br/ccivil_03/leis. Acesso em: 19 dez. 2017.

BRASIL. Constituição da República Federativa do Brasil. Brasília-DF, 1988. Disponível em: http://www.planalto.gov.br/ccivil_03/constituicao.htm. Acesso em: 20 out. 2017.

CAMPO GRANDE, MS. Convênio, 133-A, de 30 de abril de 2014. Documento disponibilizado nos autos de processo 0900932-91.2016.8.12.0001. Disponível em: https://www.tjms. jus.br. 2016, p. 890-904.

CAMPO GRANDE, MS. Lei Complementar municipal n. 190, 22 de dezembro de 2011. Dispõe sobre o regime jurídico único dos servidores públicos do município de Campo Grande. Disponível em: http://www.campogrande.ms.gov.br/seges/downloads/leicomplementar/. Acesso em: 18 maio 2018.

CAMPO GRANDE, MS. Emenda n. 23, 11 de setembro de 2007. Alterou a Lei Orgânica do município de Campo Grande. Disponível em: https://www.camara.ms.gov.br/public/ downloads/10_lei_organica_municipal.pdf. Acesso em: 2 dez. 2018.

FERNANDES, S. J. A gestão dos fundos contábeis para o financiamento do ensino no município de Campo Grande/MS. 2013. 283 f. Tese (Doutorado em educação) Universidade Federal de Mato Grosso do Sul. Campo Grande: 2013.

MATO GROSSO DO SUL. Ação Civil de Improbidade Administrativa. Violação aos Princípios. Campo Grande, 2018a. Disponível em: http://www.tjms.jus.br Acesso em: 18 dez. 2017.

MATO GROSSO DO SUL. Tribunal de Justiça do Estado de Mato Grosso do Sul. Ação Civil de Improbidade Administrativa. 2018b. Diário da Justiça, n. 4103, 4 set. 2018. Sentença de fls. 8009-8030, Autos de Processo n. 0900932-91.2016.8.12.0001. Campo Grande, MS, 2018b. Disponível em: http://www.tjms.jus.br. Acesso em: 3 dez. 2018.

MATO GROSSO DO SUL (Estado). Tribunal de Justiça do Estado de Mato Grosso do Sul. Ação Civil Pública, com pedido de tutela antecipada. Campo Grande, 2016a. Disponível em: http://www.tjms.jus.br. Acesso em: 18 maio 2018.

MATO GROSSO DO SUL . Execução de Título Extrajudicial. Obrigação de Fazer/Não Fazer. Campo Grande, 2016b. Disponível em: http://www.tjms.jus.br. Acesso em: 18 dez. 2017.

MIDIAMAX. Prefeitura anuncia demissão de funcionários da OMEP e Seleta até janeiro. Jornal Eletrônico Midiamax, Campo Grande, 31 maio 2016. Cotidiano. Disponível em: https://www.midiamax.com.br/cotidiano/2016/prefeitura-anuncia-demissao-defuncionarios-da-omep-e-seleta-ate-janeiro/. Acesso em: 11 jul. 2016. 
MONTAÑO, C. Terceiro Setor e questão social: crítica ao padrão emergente da intervenção social. 6. ed. São Paulo: Cortez, 2010.

PERONI, V. M. V. Implicações da relação público-privada para a democratização da educação. 2015.181 f. Tese (Promoção a Professor Titular da Carreira do Magistério Superior) - Faculdade de Educação, Universidade Federal do Rio Grande do Sul, Porto Alegre, 2015.

PERONI, V. M. V. Múltiplas Formas de Materialização do Privado na Educação Básica Pública no Brasil: sujeitos e conteúdo da proposta. Currículo sem Fronteiras, v. 18, n. 1, p. 212-38, jan./abr. 2018.

ROBERTSON, S.; VERGER, A. A origem das parcerias público-privada na governança global da educação. Educação e Sociedade, Campinas, v. 33, n. 121, p. 1133-56, 2012.

SZAZI, Eduardo. Terceiro Setor: regulação no Brasil. 4. ed. São Paulo: Peirópolis, 2006.

\section{Sobre as autoras:}

Solange Jarcem Fernandes: Professora adjunta da Faculdade de Educação da Universidade Federal de Mato Grosso do Sul (UFMS). Atua nos cursos de Licenciatura e no Programa de Pós-Graduação de Mestrado e Doutorado em Educação dessa universidade, nas áreas de Políticas Educacionais, Gestão da Educação Básica, Financiamento Público da Educação Básica e Metodologia Científica. E-mail: solangejarcem@gmail.com, Orcid: http://orcid.org/0000-0003-0287-6172

Andrêssa Gomes de Rezende Alves: Doutora e mestre em Educação pela Universidade Federal de Mato Grosso do Sul (UFMS). Graduada em Pedagogia pela mesma universidade. Professora adjunta da Universidade Estadual de Mato Grosso do Sul (UEMS). E-mail: andressa_rezende@hotmail.com, Orcid: http://orcid.org/0000-0002-2344-454X

ElayneSilva Viana:Mestrandaem Educaçãoegraduadaem Pedagogia pela Universidade Federal de Mato Grosso do Sul (UFMS). Bacharel em Direito pela Universidade Católica Dom Bosco (UCDB). E-mail: elaynevianaadvogada@gmail.com, Orcid: http://orcid.org/0000-0002-6752-1164

\section{Recebido em 08/11/2019 \\ Aprovado em 31/01/2020}

